\title{
Gregarina niphandrodes may Lack Both a Plastid Genome and Organelle
}

\author{
MARC A. TOSO and CHARLOTTE K. OMOTO \\ School of Biological Sciences, Washington State University, Pullman, Washington 99164-4236
}

\begin{abstract}
Gregarines are early diverging apicomplexans that appear to be closely related to Cryptosporidium. Most apicomplexans, including Plasmodium, Toxoplasma, and Eimeria, possess both plastids and corresponding plastid genomes. Cryptosporidium lacks both the organelle and the genome. To investigate the evolutionary history of plastids in the Apicomplexa, we tried to determine whether gregarines possess a plastid and/or its genome. We used PCR and dot-blot hybridization to determine whether the gregarine Gregarina niphandrodes possesses a plastid genome. We used an inhibitor of plastid function for any reduction in gregarine infection, and transmission electron microscopy to search for plastid ultrastructure. Despite an extensive search, an organelle of the appropriate ultrastructure in transmission electron microscopy, was not observed. Triclosan, an inhibitor of the plastid-specific enoyl-acyl carrier reductase enzyme, did not reduce host infection by G. niphandrodes. Plastid-specific primers produced amplicons with the DNA of Babesia equi, Plasmodium falciparum, and Toxoplasma gondii as templates, but not with G. niphandrodes DNA. Plastid-specific DNA probes, which hybridized to Babesia equi, failed to hybridize to G. niphandrodes DNA. This evidence indicates that G. niphandrodes is not likely to possess either a plastid organelle or its genome. This raises the possibility that the plastid was lost in the Apicomplexan following the divergence of gregarines and Cryptosporidium.
\end{abstract}

Key Words. Apicomplexa, apicoplast, fatty acid synthesis, gregarine.

$\mathrm{T}$ HE phylum Apicomplexa consists of unicellular parasites that infect a wide variety of hosts. Apicomplexans that cause diseases in humans or livestock, such as coccidiosis, babesiosis, toxoplasmosis, and malaria, are well studied. Gregarines are apicomplexans that infect invertebrates and have primarily a monoxenous life cycle. They are considered to represent an early diverging apicomplexan lineage, thus making them a key group for questions regarding apicomplexan evolution. Phylogenetic analyses of the small subunit (SSU) ribosomal RNA (rRNA) gene suggests the gregarines are a sister group to Cryptosporidium, and represent an early divergence within the phylum Apicomplexa (Carreno, Martin, and Barta 1999; Leander, Clopton, and Keeling 2003). Life-cycle characteristics shared between gregarines and Cryptosporidium also suggest that these two groups are sisters (Hijjawi et al. 2002; Rosales et al. 2005).

Apicoplasts are non-photosynthetic plastids found in a number of apicomplexans (Lang-Unnasch et al. 1998). Discovery of the $\sim 35-40 \mathrm{~kb}$ plastid genome was a surprise as apicomplexans are non-photosynthetic. However, the presence of plastid DNA indicated that they had a photosynthetic ancestor (Cai et al. 2004; Kohler et al. 1997; McFadden and van Dooren 2004). To date, four species of apicomplexans have had their entire plastid DNA sequenced: Plasmodium falciparum (Wilson et al. 1996), Theileria parva (Gardner et al. 2005), Toxoplasma gondii, and Eimeria tenella (Cai et al. 2004). The genes encoded by the small apicoplast genome constitute only a small fraction of the gene products in the apicoplast. Owing to the extensive gene transfer from the plastid to the nucleus most of the plastid-localized proteins are encoded in the nuclear DNA (Waller et al. 1998).

Cryptosporidium is the only member of the phylum Apicomplexa in which a plastid has been sought but not found. Analysis of the complete genomes of $C$. parvum and C. hominis identified neither a plastid genome nor genes with putative plastid-targeting sequences (Abrahamsen et al. 2004; Xu et al. 2004). Primers designed to amplify plastid-encoded sequences failed to produce products with Cryptosporidium DNA, yet did produce products using $T$. gondii and $B$. bovis DNA as templates. Likewise, apicomplexan plastid probes failed to hybridize to C. parvum DNA, yet hybridized to DNA from $T$. gondii, $P$. falciparum, and $E$. bovis (Zhu, Marchewka, and Keithly 2000a). Plastid-like structures have not been revealed through microscopy of Cryptosporidium

Corresponding Author: C. K. Omoto, School of Biological Sciences, Washington State University, PO Box 4236, Pullman, WA 99164-4236, USA-Telephone number: +1-509-335-5591; FAX number: +1-509335-3184; e-mail: omoto@wsu.edu
(Riordan et al. 2003). Cyanobacterial-like genes have been discovered in Cryptosporidium; however, they lack plastid-targeting sequences (Huang et al. 2004). Together this evidence indicates that Cryptosporidium does not have a plastid genome or the organelle.

A common pathway among plastid bearing organisms is the Type II fatty acid synthesis (FAS II) pathway. This pathway is associated with both plants (Harwood 1996) and apicomplexan plastids (Waller et al. 1998) and is derived from the plastid's ancestral endosymbiont. Inhibitors to this pathway have been shown to stymie $P$. falciparum growth and survival (Surolia and Surolia 2001). Cryptosporidium lacks the FAS II pathway and compounds that inhibit this pathway have no effect on Cryptosporidium (Zhu et al. 2000b), providing further supporting evidence that Cryptosporidium lacks a plastid.

The lack of a plastid in Cryptosporidium raises the question of when this organelle was introduced or lost in the apicomplexan lineage. That is, did the lineage leading to apicomplexans have plastids and subsequently the branch leading to Cryptosporidium lose them? Alternatively, did the incorporation of this organelle occur in the apicomplexan lineage after the branch leading to Cryptosporidium? Whether gregarines have a plastid is key to answering these questions.

\section{MATERIALS AND METHODS}

Collection of gametocysts from Gregarina niphandrodes. Briefly, gametocysts from G. niphandrodes were collected from the frass of adult Tenebrio molitor, separated on a step sucrose gradient, manually collected, extensively washed in sterile distilled water, and stored in ethanol at $-20^{\circ} \mathrm{C}$ (Omoto et al. 2004). Gametocysts collected in the triclosan drug study were not dehydrated in ethanol so that they could be returned to their respective host populations.

Extraction of DNA from gametocysts of Gregarina niphandrodes. Ethanol-preserved gametocysts from G. niphandrodes were hydrated in sterile distilled water. The samples were frozen for $20 \mathrm{~min}$ at $-80{ }^{\circ} \mathrm{C}$ and incubated at $50{ }^{\circ} \mathrm{C}$ for $15 \mathrm{~min}$ in lysis buffer (50 mM Tris-HCl, pH 8, $200 \mathrm{mM} \mathrm{NaCl}, 1$ mM EDTA, $\mathrm{pH} 8,1 \%$ [w/v] SDS, $0.2 \%$ [v/v] DTT). DNA was extracted using standard phenol-chloroform-isoamyl extraction and ethanol precipitation. The final pellet was suspended in sterile distilled water.

PCR. Six pairs of degenerate plastid-specific primers were used to amplify highly conserved regions of the plastid genome (Table 1) (Zhu et al. 2000a). To account for mismatched bases between template DNA and primers a $5 \mathrm{mM}$ magnesium 
Table 1. Polymerase chain reaction primers.

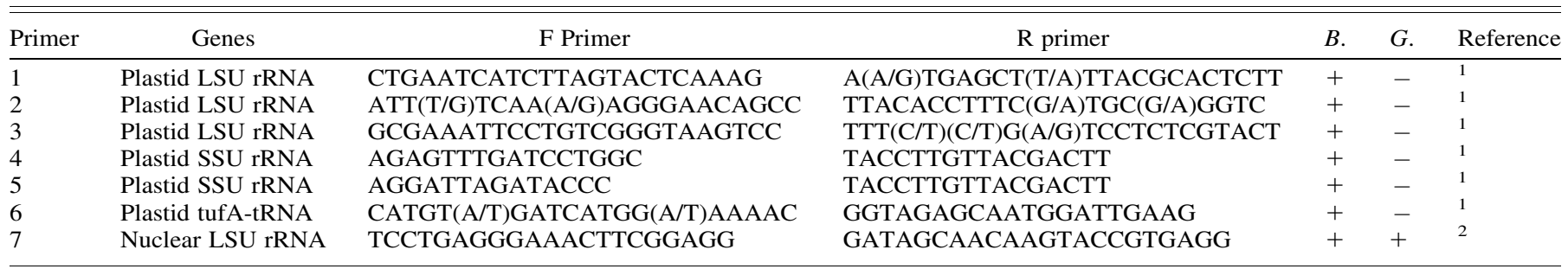

Amplicons produced (+) or not produced ( - ) with B, Babesia equi DNA; G, Gregarina niphandrodes DNA; LSU, large subunit; SSU, small subunit. ${ }^{1}$ Zhu et al. (2000a).

${ }^{2}$ This study.

concentration and annealing temperature of $48{ }^{\circ} \mathrm{C}$ were used. DNA from B. equi, $P$. falciparum, and $T$. gondii was used for plastid positive controls. Primers designed to amplify the nuclear large subunit (LSU) rRNA gene from $G$. niphandrodes were used for the positive control for $G$. niphandrodes DNA (Table 1). Polymerase chain reaction products were separated by electrophoresis using $1 \%(\mathrm{w} / \mathrm{v})$ Tris-Acetate-EDTA agarose.

Babesia equi products ( ${ }^{*}$, Fig. 1) were excised from the gel, reamplified, and sequenced. DNA sequencing was carried out by the DyeDeoxy terminator cycle protocol with synthetic primers synthesized by Invitrogen (Carlsbad, CA). Sequencing reactions were analyzed on an Applied Biosystems 377 DNA Sequencer at the Washington State University Laboratory of Bioanalysis and Biotechnology.

Triclosan/bran preparation. Triclosan (Irgasan $^{\mathrm{TM}}$, SigmaAldrich), was dissolved in acetone and applied to wheat bran at two concentrations: $4 \mathrm{mg} / \mathrm{g}$ of bran and $0.4 \mathrm{mg} / \mathrm{g}$ bran. The

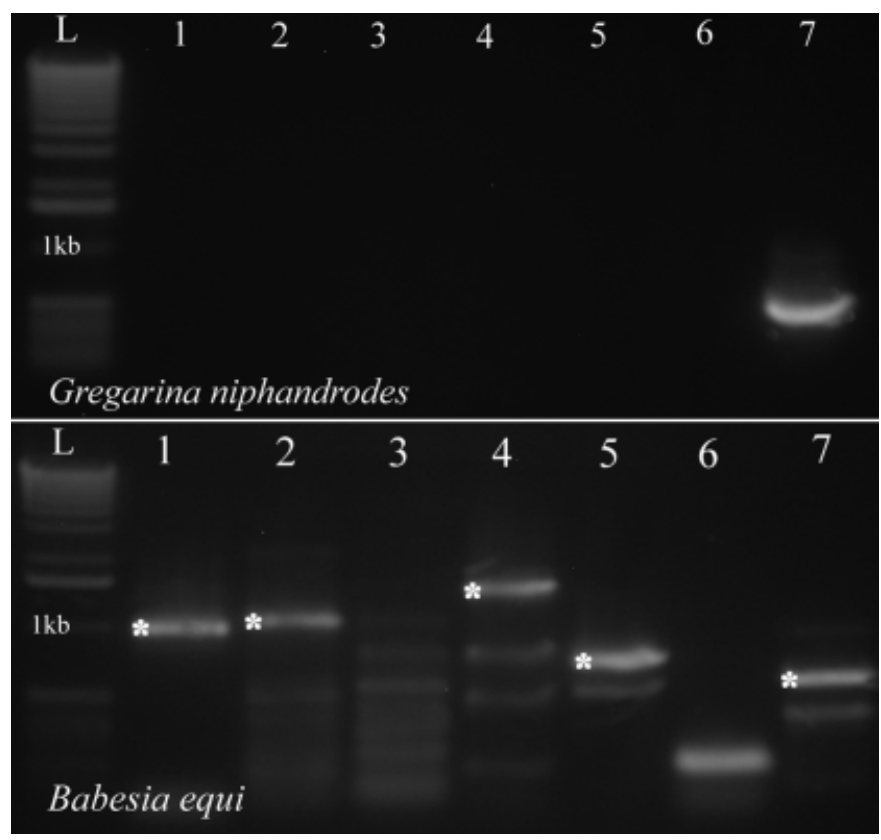

Fig. 1. Agarose gel of polymerase chain reaction products. No amplicons were produced with plastid-specific primers using DNA from Gregarina niphandrodes as template (upper row, lanes 1-6) whereas all of the primer pairs produced amplicons using Babesia equi DNA template (lower row, lanes 1-6). Only the large subunit (LSU) rRNA primers produced an amplicon with G. niphandrodes DNA (lane 7). Numbers correspond to primer pairs listed in Table 1. Plastid-specific primers (lanes 1-6), nuclear LSU rRNA primers (lane 7), L, a $1 \mathrm{~kb}$ ladder, the $1 \mathrm{~kb}$ band is labeled. *Bands that were reamplified and sequenced. acetone was allowed to evaporate completely overnight in a fume hood. Control with just acetone was also prepared.

Beetle care. Fifty adult beetles (T. molitor) from the laboratory stock of beetles infected with $G$. niphandrodes were placed in each concentration of the triclosan/bran mixture. Beetles were tested in triplicate at each concentration of triclosan.

The bran with beetles was covered with an unbleached paper towel. Four milliliters of water were dropped on the paper towel daily. Every 7 days the numbers of beetles were counted and gametocysts were collected from each group as described above and replaced in the container. The bran was replaced every 7 days with triclosan-acetone-treated bran for each group's respective treatment. This was continued for 42 days.

Thin layer chromatography (TLC). To determine the level of triclosan in the intestinal environment of the gregarines, TLC was used. After $1 \mathrm{wk}$, five beetles each from the $0.4 \mathrm{mg} / \mathrm{g}$ and the $4.0 \mathrm{mg} / \mathrm{g}$ groups were dissected and the intestines were frozen at $-20^{\circ} \mathrm{C}$ for $20 \mathrm{~min}$ in $1.5 \mathrm{ml}$ microfuge tubes. The tissue was homogenized and the triclosan extracted with a $1: 1(\mathrm{v} / \mathrm{v})$ mixture of methanol:chloroform. An intestine from a beetle in the acetone group was used as a negative control. For a triclosan positive control, an intestine from a beetle unexposed to triclosan was used, but spiked with $1.5 \mu \mathrm{g}$ of triclosan prior to extraction. The samples were analyzed on Silica Gel 60F254 TLC sheet (EM Separations) with chloroform as solvent and visualized under short wavelength UV illumination.

Determination of triclosan concentration in beetle intestine. The intestines of five beetles were placed in a graduated $1.5 \mathrm{ml}$ microfuge tube and centrifuged for $1 \mathrm{~min}$ at $13,000 \mathrm{~g}$ to estimate the intestine vol. Five intestines occupied approximately $\sim 100 \mu \mathrm{l}$; thus, the average volume of a beetle intestine is $\sim 20 \mu 1$. To estimate the quantity of triclosan in the beetle intestine, a triclosan standard from 0.2 to $1.6 \mu \mathrm{g}$ TLC was made. This standard was then visually compared with the TLC from each triclosan-exposed beetle. The quantity of triclosan found in the intestines of drugged beetles divided by the intestinal volume provided an estimated concentration of triclosan in the intestines. Our procedure for volume estimate will err on the high end, and thus lower the estimate for the triclosan concentration.

Determination of gregarine infection. The level of gregarine infection was assessed by counting gametocysts weekly. As beetles naturally died over time, the ratio of gametocysts per beetle was calculated. The natural $\log$ of this ratio was used as the response variable in our analysis. We performed a repeated measures analysis of variance (ANOVA) with time (the seven time points) and treatment (control/acetone, $4.0 \mathrm{mg} / \mathrm{g}, 0.4 \mathrm{mg} / \mathrm{g}$ ) as our factors. The log-transformed response satisfied the assumptions of normality and homogeneity of variances.

At the end of the experimental treatment, five beetles from each group were selected at random for dissection. The dissected intestines were placed in insect Ringer's (120 mM NaCl, $1.2 \mathrm{mM}$ 
$\mathrm{KCl}, 1.4 \mathrm{mM} \mathrm{CaCl} 2$ ), and the trophozoites were counted under a dissecting microscope. Trophozoite counts were log-transformed as above and analyzed using a one-way ANOVA to assess the differences between the three treatments.

Transmission electron microscopy. Trophozoites of G. niphandrodes were dissected from T. molitor in insect Ringer's solution and fixed overnight at $4{ }^{\circ} \mathrm{C}$ in $2 \%(\mathrm{w} / \mathrm{v})$ paraformaldehyde and $2 \%(\mathrm{v} / \mathrm{v})$ glutaraldehyde in $0.1 \mathrm{M}$ cacodylate buffer, $\mathrm{pH}$ 7.2. Samples were rinsed three times in $0.1 \mathrm{M}$ cacodylate buffer before a $1 \mathrm{~h}$ postfix with $2 \%(\mathrm{w} / \mathrm{v})$ osmium tetroxide in $0.1 \mathrm{M}$ cacodylate buffer. They were rinsed three times in distilled water and stained in $1 \%(\mathrm{w} / \mathrm{v})$ tannic acid for $1 \mathrm{~h}$. For potassium permanganate fixation, trophozoites were fixed overnight with $1 \%(\mathrm{w} / \mathrm{v})$ potassium permanganate in $0.1 \mathrm{M}$ veronal acetate buffer. The trophozoites were then washed three times in the buffer. All the specimens were dehydrated in an acetone series and embedded in Spurr's resin. Ultrathin sections were cut with a glass knife on a Leica Reichert microtome and placed on formvar-coated copper grids. Sections were stained with uranyl acetate and Sato's lead. Samples fixed with potassium permanganate were viewed unstained. The samples were viewed on a JEOL 1200 EX transmission electron microscopy (TEM). Five trophozoites each from the paraformaldehyde/glutaraldehyde fixation and potassium permanganate fixation were serially sectioned longitudinally. As trophozoites are large, one section covers a large proportion of the grid $(\sim 300 \mu \mathrm{m} \times \sim 125 \mu \mathrm{m}$ per cell). At least three whole sections were examined from each cell.

Dot-blot hybridizations. Hybridizations were performed according to the manufacturer's directions (Boehringer Mannheim DIG System Users Guide). Five-hundred nanograms of total DNA from $G$. niphandrodes and $B$. equi were denatured by boiling for $10 \mathrm{~min}$, placed on ice, and then dotted onto a Nytran Plus (Florham Park, NJ) nylon membrane. The DNA was cross-linked to the membrane using a Bio-Rad GS Gene Linker (Hercules, CA). Probes used were apicoplast PCR products from $B$. equi (PCR products 1, 2, 4, and 5, Fig. 1) and LSU PCR product from $G$. niphandrodes (lane 7, Fig. 1) labeled with digoxigenin using the PCR DIG Probe Synthesis Kit (Roche Diagnostics, Basel, Switzerland). Probes were denatured by boiling for $10 \mathrm{~min}$ followed by icing. The membrane was pre-hybridized with DIG Easy Hyb buffer (Roche Diagnostics) at $42{ }^{\circ} \mathrm{C}$ for $2 \mathrm{~h}$. Hybridization was performed overnight at $42{ }^{\circ} \mathrm{C}$ with the DIG-labeled B. equi probes in Easy Hyb buffer. After hybridization, the membrane was washed three times in $2.0 \times \mathrm{SSC}$ and $0.1 \%(\mathrm{w} / \mathrm{v}) \mathrm{SDS}$ at $50{ }^{\circ} \mathrm{C}$. Detection of probe was performed using anti-DIG-AP conjugate (Roche Diagnostics) and the luminescence signal was detected and imaged using an AutoBiochemi (UVP, Upland, CA) system. The membrane was stripped by incubating two times for $20 \mathrm{~min}$ in $0.2 \mathrm{M} \mathrm{NaOH}$ and $0.1 \%$ SDS at $37^{\circ} \mathrm{C}$. The membrane was rinsed in $2.0 \times \mathrm{SSC}$ and used again directly for hybridization.

\section{RESULTS}

PCR analysis of DNA from Gregarina niphandrodes. Polymerase chain reaction was performed to investigate if G. niphandrodes possesses DNA sequences similar to those found in other apicomplexan plastids. Six plastid-specific primer pairs designed against highly conserved regions of the plastid genome (Table 1) did not produce any products using $G$. niphandrodes DNA as a template despite numerous attempts with different PCR conditions (top row, lanes 1-6, Fig. 1). Products were amplified with primers pairs using $B$. equi DNA as a template (bottom row, lanes 1-6, Fig. 1). The PCR conditions used favored primer hybridization with a slight mismatch in the primer sequence for both B. equi and G. niphandrodes DNA. The multiple bands observed with $B$. equi DNA as template is attributed to our use of these

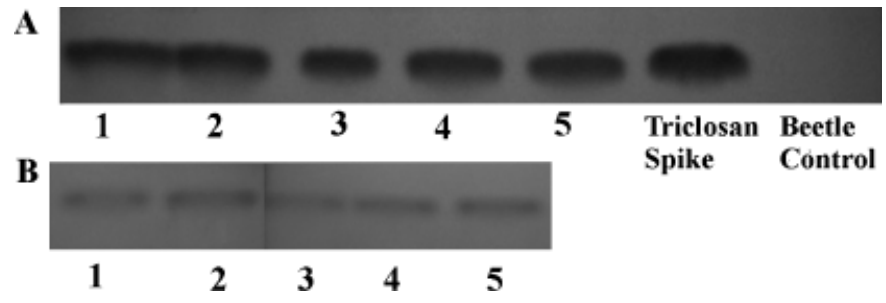

Fig. 2. Triclosan extracted from the intestines of Tenebrio molitor using thin layer chromatography. (A) Seven intestines derived from beetles exposed to triclosan at $4.0 \mathrm{mg} / \mathrm{g}$ bran (lanes 1-5), a triclosan spike of $1.5 \mu \mathrm{g}$ (lane 6), and an acetone control (lane 7). (B) Five intestines from beetles exposed to triclosan at $0.4 \mathrm{mg} / \mathrm{g}$ of bran.

conditions, as we did not try to optimize the conditions to produce a single amplicon band.

The B. equi products (*, Fig. 1) were re-amplified and sequenced to determine whether the products were indeed apicoplast sequences. These sequences had highly significant matches to apicoplast genome sequences: for example, the sequence of the product in lane 4 matched $B$. bigemina apicoplast small subunit ribosomal RNA gene (Accession number: AF040968) with an $e$ value of $1 e^{-20}$. Thus, the plastid-specific primers amplified plastid sequences of $B$. equi DNA.

We also used primer pairs 1 and 5 with $T$. gondii and $P$. falciparum DNA as templates, and they, too, produced products (data not shown). Yet, no plastid-specific primers amplified products from G. niphandrodes DNA. However, primers designed to amplify the conserved nuclear LSU rRNA produced an amplicon with both G. niphandrodes and B. equi DNA (lane 7, Fig. 1). The sequence of G. niphandrodes product from lane 7 (Accession number: DQ837379) has a highly significant match to other apicomplexan nuclear LSU rRNA. The G. niphandrodes DNA has also been used to amplify and sequence the largest subunit of the DNA-dependent RNA polymerase (RPB1), which is a nuclear protein-encoding gene (Accession number: AY168016). Thus, the quality of $G$. niphandrodes was sufficient for PCR amplification, but it did not produce any product using plastid-specific primers designed for highly conserved apicoplast sequences.

Triclosan drug studies. Intestines from five beetles each from low and high triclosan treatments $(0.4 \mathrm{mg} / \mathrm{g}$ bran and $4 \mathrm{mg} / \mathrm{g}$ bran $)$ and acetone control, and an unexposed beetle but spiked with $1.5 \mu \mathrm{g}$ of triclosan were extracted and analyzed. Triclosan was not detectable in the intestine of a beetle unexposed to the triclosan (Fig. 2). The beetles exposed to $0.4 \mathrm{mg} / \mathrm{g}$ triclosan bran had $\sim 0.3 \mu \mathrm{g}$ triclosan. The beetles exposed to $4.0 \mathrm{mg} / \mathrm{g}$ triclosan bran had $\sim 1.5 \mu \mathrm{g}$ triclosan. Using $\sim 20 \mu \mathrm{l}$ as the volume of an intestine, the triclosan concentration is estimated to be $\sim 15,000 \mathrm{ng} / \mathrm{ml}$ at the lower dose of triclosan and $\sim 75,000 \mathrm{ng} /$ $\mathrm{ml}$ in the high triclosan treatment.

To determine the effect of triclosan exposure on gregarine infestation of beetles, gametocysts released in the frass of the beetles were counted weekly for $7 \mathrm{wk}$. The results indicated no treatment effect $(F=0.15 ; P=0.860)$ with no effect of time and no treatment interaction $(F=0.86 ; P=0.589)$.

After the final collection of gametocysts at week 7, five beetles from each group were dissected to determine the degree of trophozoite infection. The huge variance between the numbers of trophozoites between individuals is evident in the large standard deviation for the average number of trophozoites: control (18.4 \pm 26.5), $0.4 \mathrm{mg} / \mathrm{g}(33.3 \pm 42.3)$, and $4.0 \mathrm{mg} / \mathrm{g}(44.5 \pm 56.0)$. The higher number of trophozoites in both triclosan treatments compared with the control and the higher number of trophozoites in the higher concentration of triclosan was slightly significant $(F=4.53 ; P=0.017)$. Thus, triclosan, a specific inhibitor of 

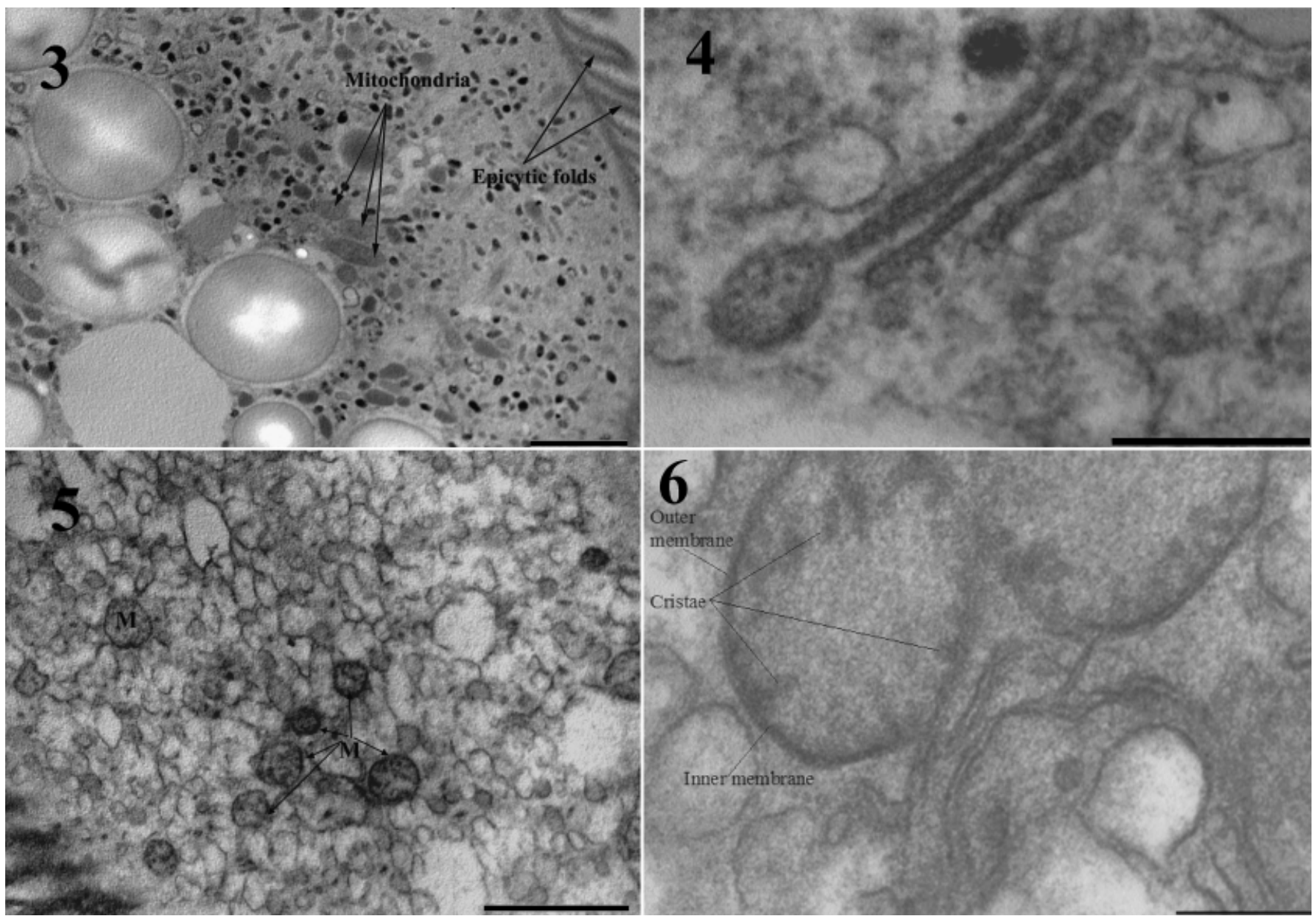

Fig. 3-6. Transmission election micrographs (TEM) of trophozoites of Gregarina niphandrodes fixed with paraformaldehyde and glutaraldehyde $(3,4)$ and with permanganate $(5,6)$. 3. Mitochondria and epicytic folds are clearly seen. Scale bar $=1 \mu$ m. 4. Higher magnification TEM of G. niphandrodes showing a Golgi complex. Scale bar $=0.2 \mu \mathrm{m}$. 5. Numerous mitochondria $(\mathrm{M})$ are visible. Scale bar $=1 \mu \mathrm{m}$. 6. Higher magnification TEM of G. niphandrodes mitochondria. Outer membrane, inner membrane, and cristae are visible. Scale bar $=200 \mathrm{~nm}$.

FAS II pathway, if anything, increased rather than decreased gregarine infestation.

Electron microscopy. Transmission electron microscopy was used to search for plastid-like organelles. Both fixative treatments revealed mitochondrion-like structures (Fig. 3, 5, 6). Despite extensive searches through multiple sections from 10 different trophozoites, no multi-membranous organelle characteristic of plastids was observed. Other membranous organelles, such as epicytic folds and Golgi (Fig. 4) were visible. While potassium permanganate fixation is poor overall, it is useful for revealing membranes, making it an ideal method to reveal multi-membranous organelles, like the plastid. Using this fixation, mitochondria were clearly seen scattered throughout the cytoplasm (Fig. 5). At higher magnification, the details of the mitochondria, their cristae and the dual membranes, are visible (Fig. 6). Various examples of cytoplasm are visible in Fig. 7-10, no structures were observed with features reminiscent of plastids in any sections.

Dot-blot hybridization. Hybridizations were also used to investigate if $G$. niphandrodes possesses plastid DNA. A mixture of LSU and SSU plastid sequences from $B$. equi plastid DNA (total of $\sim 4 \mathrm{~kb}$ ) was used to probe for plastid DNA. The hybridizations were performed at a lower stringency to allow for cross species hybridization. The plastid probes hybridized to total DNA from $B$. equi. However, there was no hybridization signal with $G$. niphandrodes DNA (Fig. 11A). The nuclear LSU probe from G. nip- handrodes hybridized to both the G. niphandrodes and B. equi DNA (Fig. 11B).

\section{DISCUSSION}

We used PCR, an inhibitor specific to a plastid pathway, thinsection electron microscopy, and dot-blot hybridization to investigate whether $G$. niphandrodes has a plastid. None of the four approaches provided any evidence to suggest that $G$. niphandrodes possesses a plastid.

No amplicons were obtained with plastid-specific primers using G. niphandrodes DNA as a template. This DNA produced amplicons with primers to nuclear LSU and to a nuclear proteinencoding gene, RPB1, clearly demonstrating that the DNA was of sufficient quality to amplify sequences. The plastid-specific primers have been shown to amplify DNA from numerous apicomplexan species, as well as chloroplast DNA (Zhu et al. 2000a), and we produced amplicons using $B$. equi, $T$. gondii and $P$. falciparum templates as positive controls. Thus, if $G$. niphandrodes possesses a plastid genome, our results indicate that its sequence must be significantly divergent from those of other organisms harboring plastids. Obornik et al. (2002) also tried to determine whether the gregarine Gregarina garnhami possessed a plastid genome using a plastid-specific SSU rRNA PCR primers but they also could not produce a product. 


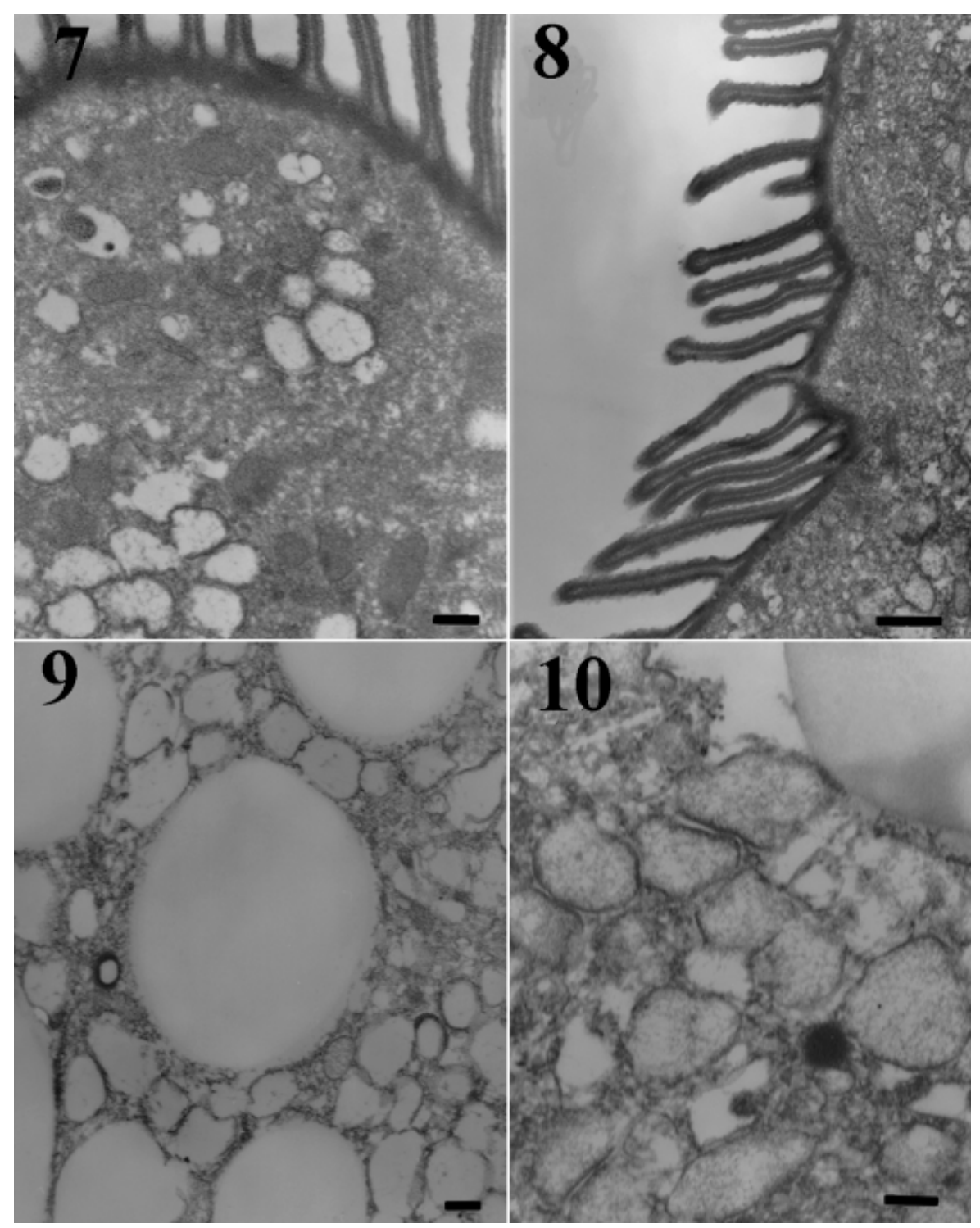

Fig. 7-10. Transmission election micrographs (TEM) of epicytic folds $(7,8)$ and cytoplasm $(7,9,10)$ of Gregarina niphandrodes trophozoites. 7. Epicytic folds and mitochondria are visible in G. niphandrodes. Scale bar $=200 \mathrm{~nm}$. 8. TEM of epicytic folds in G. niphandrodes. Scale bar $=500 \mathrm{~nm}$. 9 . TEM of G. niphandrodes cytoplasm showing large vacuoles. Scale bar $=200 \mathrm{~nm}$. 10. TEM of typical cytoplasm and G. niphandrodes trophozoite. Scale bar $=200 \mathrm{~nm}$.

We investigated whether triclosan reduced the level of G. niphandrodes infection in $T$. molitor. We initially tested a range of triclosan concentrations to determine the maximum concentration that did not cause significant beetle mortality over a 1 -wk period (data not shown). We then used triclosan at that concentration, $4 \mathrm{mg} / \mathrm{g}$ bran, and also at 10 -fold lower concentration.

The FASII pathway is found in all organisms harboring plastids (Harwood 1996; Ryall, Harper, and Keeling 2003; Waller et al. 1998). Within this pathway, ENR is inhibited by the compound triclosan in bacteria (Escalada et al. 2005) and in other apicomplexans that contain plastids (McLeod et al. 2001; Surolia and Surolia 2001). Cryptosporidium synthesizes fatty acids with a giant multienzymatic Type I FAS (Zhu 2004) and not by the FASII (Abrahamsen et al. 2004; Xu et al. 2004; Zhu et al. 2000a). Consequently, it is unaffected by inhibitors of the FASII pathway (Zhu 2004). If G. niphandrodes contained a plastid, we expected triclosan treatment to inhibit the FASII and significantly decrease the number of gametocysts and trophozoites. There was no stat- istically significant reduction in gametocyst production with triclosan treatment. Unexpectedly, there were higher numbers of trophozoites in the triclosan treatments compared with controls, though it was only slightly statistically significant. Thus, triclosan clearly does not decrease the level of gregarine infection in $T$. molitor adults. The higher trophozoite numbers in triclosan-treated beetles and higher trophozoite numbers in the higher triclosan treatment may be explained by triclosan inhibition of the bacterial flora within the intestine. The bacteria may act as competitors to gregarine growth and/or survival. Hence, inhibiting the bacteria with triclosan may indirectly benefit gregarines and lead to higher survival.

Triclosan inhibits ENR through the binding of specific amino acids; bacteria (E. coli), plants (B. napus), and P. falciparum all share identical amino acid sequence at this binding site, indicating a conserved target for triclosan in a wide range of organisms (McLeod et al. 2001). Previous studies on apicomplexans used direct application of triclosan on the parasites to inhibit growth 


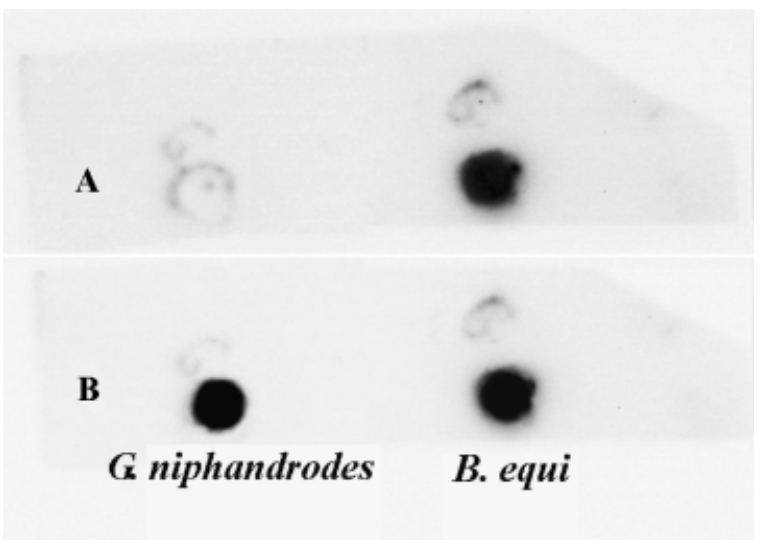

Fig. 11. Dot-blot of DNA from Gregarina niphandrodes and Babesia equi. (A) A mixture of large subunit (LSU) and small subunit (SSU) apicoplast sequences from $B$. equi were used as a probe (see polymerase chain reaction [PCR] products $1,2,4$, and 5, Fig. 1). DNA from B. equi gave a strong signal while G. niphandrodes DNA did not produce any signal. (B) The nuclear LSU sequence from $G$. niphandrodes as a probe (PCR product 7, Fig. 1) gave very strong signals to both $G$. niphandrodes and $B$. equi DNA.

and survival. However, we cannot grow gregarines in the absence of the host. Therefore, we grew the hosts in triclosan to determine its effect upon $G$. niphandrodes. We estimated the concentration of triclosan in the intestine to be $\sim 15,000 \mathrm{ng} / \mathrm{ml}$ at the lower exposure concentration of triclosan. Previous studies showed that direct exposure of $150 \mathrm{ng} / \mathrm{ml}$ for $P$. falciparum and $62 \mathrm{ng} / \mathrm{ml}$ for $T$. gondii inhibited their growth (McLeod et al. 2001). Thus, our gregarines were estimated to be exposed to at least 100 times the concentration of triclosan shown to be inhibitory in previous studies.

Triclosan clearly did not decrease gregarine infestation. Indeed, perhaps the increased gregarine infestation strongly indicates that G. niphandrodes lacks this common plastid localized enzyme. Gregarina niphandrodes may obtain fatty acids from its host, $T$. molitor, making this pathway unessential. However, in that case, it suggests that it may also not require a plastid. This triclosan study is the first to probe the fatty acid metabolism of gregarines, suggesting G. niphandrodes, like Cryptosporidium, may lack the FASII pathway.

The apicoplast is a multimembranous organelle. Two to four membranes have been observed in the Apicomplexa (Hopkins et al. 1999; Kohler et al. 1997; McFadden et al. 1996). The observation of three or four membranes led to the hypothesis that the apicoplast arose through secondary endosymbiosis of an alga. However, studies of the $T$. gondii apicoplast have revealed two membranes that undergo complex in-foldings, in effect revealing three to four membrane layers in thin section. Such a structure suggests an alternative evolutionary pathway for the plastid in $T$. gondii as a primary endosymbiosis of a cyanobacteria (Kohler 2005). We looked for a multimembranous organelle characteristic of plastid ultrastructure in TEM. No organelle with this ultrastructure was observed. Common membranous structures were seen, such as mitochondria and Golgi. The application of permanganate fixation, which is particularly useful for revealing multi-membrane structures, revealed the dual membrane mitochondria, but also failed to reveal plastid-like organelles.

Dot-blot hybridization also failed to demonstrate a plastid genome in $G$. niphandrodes. The experiment was performed using probes that encompass significant portion of highly conserved plastid sequences at lower stringency to allow for hybridization of mismatched bases between the probe DNA of B. equi and G. nip- handrodes. The apicoplast probe bound to B. equi DNA but not to G. niphandrodes DNA. This provides further support that G. niphandrodes lacks the homologues of SSU and LSU apicoplast sequences. A nuclear LSU G. niphandrodes probe was used as a positive control. This hybridization was performed at a low stringency to replicate the conditions of the apicoplast probe hybridizations. The nuclear LSU probe bound to both $G$. niphandrodes and $B$. equi DNA.

Collectively these four studies provide strong evidence that $G$. niphandrodes may not possess either a plastid organelle or a plastid genome. The shared ancestry of apicomplexan plastids with dinoflagellate plastids implies that the common ancestor of the Apicomplexa, and thus the ancestor of gregarines and Cryptosporidium harbored a plastid. Studies of the nuclear-encoded plastid targeted glyceraldehyde-3-phosphate dehydrogenase (GAPDH) gene indicate a common origin of the apicomplexan plastids and the dinoflagellate plastids and its cyanobacterial/algal origin (Fast et al. 2001). Consistent with this hypothesis, analysis of the genome of $C$. parvum revealed several genes of cyanobacterial/algal origin (Huang et al. 2004). The close relationship between gregarines and Cryptosporidium within the Apicomplexa and the possible absence of a plastid in both suggest that the plastid was lost following the divergence of Cryptosporidium and gregarines from the other apicomplexan species harboring a plastid.

\section{ACKNOWLEDGMENTS}

We thank the WSU Franceschi Microscopy and Imaging Center, namely Chris Davitt, Valerie Lynch-Holm, and the late Vince Franceschi for assistance and guidance in microcopy, Eric Roalson for help and insight, Don Knowles and Lowell Kappmeyer for B. equis DNA and technical assistance, Jean Feagin for T. gondii and $P$. falciparum DNA and helpful advice, Michelle Martin and Kyle Martin, for gametocysts collection, Derek Pouchnik, WSU Laboratory for Bioanalysis and Biotechnology, for DNA sequencing, Dr. John Janovy, University of Nebraska, Lincoln, for instruction with T. molitor and gregarine care, John Dahl and Eric Shelden for technical assistance, and Nairanjana Dasgupta, for statistical analysis of the triclosan data.

\section{LITERATURE CITED}

Abrahamsen, M., Templeton, T., Enomoto, S., Abrahante, J., Zhu, G., Lancto, C., Deng, M., Liu, C., Widmer, G., Tzipori, S., Buck, G., Xu, P., Bankier, A., Dear, P., Konfortov, B., Spriggs, H., Iyer, L., Anantharaman, V., Aravind, L. \& Kapur, V. 2004. Complete genome sequence of the apicomplexan, Cryptosporidium parvum. Science, 304:441-445.

Cai, X., Fuller, A., McDougald, L. \& Zhu, G. 2004. Apicoplast genome of the coccidian Eimeria tenella. Gene, 321:39-46.

Carreno, R., Martin, D. \& Barta, J. 1999. Cryptosporidium is more closely related to the gregarines than to coccidia as shown by phylogenetic analysis of apicomplexan parasites inferred using small-subunit ribosomal RNA gene sequences. Parasitol. Res., 85:899-904.

Escalada, M., Russell, A., Maillard, J. \& Ochs, D. 2005. Triclosan-bacteria interactions: single or multiple target sites? Lett. Appl. Microbiol., 41:476-481.

Fast, N., Kissinger, J., Roos, D. \& Keeling, P. 2001. Nuclear-encoded, plastid-targeted genes suggest a single common origin for apicomplexan and dinoflagellate plastids. Mol. Biochem. Evol., 18:418-426.

Gardner, M., Bishop, R., Shah, T., de Villiers, E., Carlton, J., Hall, N., Ren, Q., Paulsen, I., Pain, A., Berriman, M., Wilson, R., Sato, S., Ralph, S., Mann, D., Xiong, Z., Shallom, S., Weidman, J., Jiang, L., Lynn, J., Weaver, B., Shoaibi, A., Domingo, A., Wasawo, D., Crabtree, J., Wortman, J., Haas, B., Angiuoli, S., Creasy, T., Lu, C., Suh, B., Silva, J., Utterback, T., Feldblyum, T., Pertea, M., Allen, J., Nierman, W., Taracha, E., Salzberg, S., White, O., Fitzhugh, H., Morzaria, S., Venter, J., 
Fraser, C. \& Nene, V. 2005. Genome sequence of Theileria parva, a bovine pathogen that transforms lymphocytes. Science, 309:134-137.

Harwood, J. 1996. Recent advances in the biosynthesis of plant fatty acids. Biochim. Biophys. Acta, 1301:7-56.

Hijjawi, N., Meloni, B., Ryan, U., Olson, M. \& Tamavo, S. 2002. Successful in vitro cultivation of Cryptosporidium andersoni: evidence for the existence of novel extracellular stages in the life cycle and implications for the classification of Cryptosporidium. Internat. J. Parasitol., 32:1719-1726.

Hopkins, J., Fowler, R., Krishna, S., Wilson, I., Mitchell, G. \& Bannister, L. 1999. The plastid in Plasmodium falciparum asexual blood stages: a three-dimensional ultrastructural analysis. Protist, 150:283-295.

Huang, J., Mullapudi, N., Lancto, C., Scott, M., Abrahamsen, M. \& Kissinger, J. 2004. Phylogenomic evidence supports past endosymbiosis, intracellular and horizontal gene transfer in Cryptosporidium parvum. Genome Biol., 5:R88.

Kohler, S. 2005. Multi-membrane-bound structures of Apicomplexa: I. The architecture of the Toxoplasma gondii apicoplast. Parasitol. Res., 96:258-272.

Kohler, S., Delwiche, C., Denny, P., Tilney, L., Webster, P., Wilson, R., Palmer, J. \& Roos, D. 1997. A plastid of probable green algal origin in apicomplexan parasites. Science, 275:1485-1489.

Lang-Unnasch, N., Reith, M., Munholland, J. \& Barta, J. 1998. Plastids are widespread and ancient in parasites of the phylum Apicomplexa. Int. J. Parasitol., 28:1743-1754.

Leander, B., Clopton, R. \& Keeling, P. 2003. Phylogeny of gregarines (Apicomplexa) as inferred from small-subunit rDNA and beta-tubulin. Int. J. Syst. Evol. Microbiol., 53:345-354.

McFadden, G. \& van Dooren, G. 2004. Evolution: red algal genome affirms a common origin of all plastids. Curr. Biol., 14:R514-R516.

McFadden, G., Reith, M., Munholland, J. \& Lang-Unnasch, N. 1996. Plastids in human parasites. Nature, 381:482.

McLeod, R., Muench, S., Rafferty, J., Kyle, D., Mui, E., Kirisits, M., Mack, D., Roberts, C., Samuel, B., Lyons, R., Dorris, M., Milhous, W. \& Rice, D. 2001. Triclosan inhibits the growth of Plasmodium falciparum and Toxoplasma gondii by inhibition of apicomplexan Fab I. Int. J. Paraitol., 31:109-113.

Obornik, M., Jirku, M., Slapeta, J., Modry, D., Koudela, B. \& Lukeš, J. 2002. Notes on coccidian phylogeny, based on the apicoplast small subunit ribosomal DNA. Parasitol. Res., 88:360-363.
Omoto, C., Toso, M., Tang, K. \& Sibley, L. 2004. Expressed sequence tag (EST) analysis of gregarine gametocyst development. Int. J. Paraitol., 34:1261-1271.

Riordan, C., Ault, J., Langreth, S. \& Keithly, J. 2003. Cryptosporidium parvum Cpn60 targets a relict organelle. Curr. Genet., 44:138-147.

Rosales, M., Cordon, G., Moreno, M., Sanchez, C. \& Mascaro, C. 2005. Extracellular like-gregarine stages of Cryptosporidium parvum. Acta. Trop., 95:74-78.

Ryall, K., Harper, J. \& Keeling, P. 2003. Plastid-derived Type II fatty acid biosynthetic enzymes in chromists. Gene, 14:139-148.

Surolia, N. \& Surolia, A. 2001. Triclosan offers protection against blood stages of malaria by inhibiting enoyl-ACP reductase of Plasmodium falciparum. Nat. Med., 7:167-173.

Waller, R., Keeling, P., Donald, R., Striepen, B., Handman, E., Lang-Unnasch, N., Cowman, A., Besra, G., Roos, D. \& McFadden, G. 1998. Nuclear-encoded proteins target to the plastid in Toxoplasma gondii and Plasmodium falciparum. Proc. Natl. Acad. Sci. USA, 95: 12352-12357.

Wilson, R., Denny, P., Preiser, P., Rangachar, K., Roberts, K., Roy, A., Whyte, A., Strath, M., Moore, D., Moore, P. \& Williamson, D. 1996. Complete gene map of the plastid-like DNA of the malaria parasite Plasmodium falciparum. J. Mol. Biol., 216:155-172.

Xu, P., Widmer, G., Wang, Y., Ozaki, L., Alves, J., Serrano, M., Puiu, D., Manque, P., Akiyoshi, D., Mackey, A., Pearson, W., Dear, P., Bankier, A., Peterson, D., Abrahamsen, M., Kapur, V., Tzipori, S. \& Buck, G. 2004. The genome of Cryptosporidium hominis. Nature, 431: $1107-1112$.

Zhu, G. 2004. Current progress in the fatty acid metabolism in Cryptosporidium parvum. J. Eukaryot. Microbiol., 51:381-388.

Zhu, G., Marchewka, M. \& Keithly, J. 2000a. Cryptosporidium parvum appears to lack a plastid genome. Microbiology, 146:315-321.

Zhu, G., Marchewka, M., Woods, K., Upton, S. \& Keithly, J. 2000 b. Molecular analysis of a Type I fatty acid synthase in Cryptosporidium parvum. Mol. Biochem. Parasitol., 5:253-260.

Received: 07/31/06, 08/29/06; accepted: 08/29/06 